\title{
El voseo en El Salvador
}

Nelson López ${ }^{1}$

Milton Ascencio ${ }^{2}$

Recibido en Enero 2012, aprobado en Mayo 2012

\begin{abstract}
"MAMA, vos que futuro le ves a ese movimiento por la liberacion de la muj... no, nada, olvidalo "Quino (Joaquín Salvador Lavado)
\end{abstract}

\section{Resumen}

Este artículo describe y examina el uso del voseo (el empleo del vos en lugar de tú) en El Salvador, con énfasis en el aspecto sociocultural. El uso de los pronombres personales en la segunda persona del singular (vos, tú y usted) genera cierto recelo y confusión en los salvadoreños. Aunque aquí se discuten las funciones semánticas y las teorías del poder (como jerarquía social, no como poder absoluto), está claro que la gente habla sin saber de teorías. El uso de usted impone cierto respeto, distancia, afecto y hasta distinción de clases; mientras que el tú se reserva para espacios de élite o para aquellos que, como Andrés Bello, consideran que el voseo es inadecuado, relegando el vos al vulgo.

Palabras claves: voseo, solidaridad semántica y poder semántico, tuteo

\begin{abstract}
This article describes and explores the usage of the voseo (the use of the pronoun vos rather than tú) in El Salvador, with emphasis on its sociocultural aspect. The use of personal pronouns in the second person singular "you" (vos, tú and usted) generates insecurities and confusion among Salvadorans. Although this discussion whirls around semantic functions and theories of power (as social hierarchy, not absolute power), clearly, people speak without theorizing. The use of usted presupposes a certain respect, distance, affection and even distinction of social class; meanwhile, the use of tú is kept for the elite (or elite-wannabe), or for those who, like Andrés Bello, consider the voseo inadequate, relegating the vos form to the masses in a derogatory way.
\end{abstract}

Keywords: voseo, semantic solidarity and semantic power.

1 Profesor visitante de la Marquette University.

2 Director de la Escuela de Idiomas de la Universidad Don Bosco. 


\section{Introducción}

A lo largo de la historia y en diferentes culturas siempre han existido personas que nos han querido cambiar la forma de hablar. Hace casi un siglo, en la obra de teatro Pygmalión, Henry Higgins, un profesor de fonética en Londres, quería transformar la forma en que una chica vendedora de flores, Eliza Doolittle, hablaba. A Higgins le intrigaba convertirla en una chica refinada que usara el inglés apropiado. Bernard Shaw, autor de esa obra, deleitó a audiencias en todo el mundo, aunque minimizaba el inglés sub-estándar de sus personajes.

Por la misma época, Andrés Bello ${ }^{3}$ sugería que el uso del vos como la forma familiar de la segunda persona del singular era una vulgaridad y una corrupción del español:

hay en la segunda persona pluralidad ficticia cuando se dice vos por tú, representándose como multiplicado el individuo en señal de cortesía ó respeto; pero ahora no se usa este vos sino cuando se habla á Dios ó á los santos, ó en composiciones dramáticas, ó en ciertas piezas oficiales, donde lo pide la ley ó la costumbre...El vos de que se hace tanto uso en Chile en el diálogo familiar es una vulgaridad que debe evitarse, y el construirlo con el singular de los verbos, una corrupción insoportable.

Y vos, amigo lector, seguramente ya habrás oído que el español puro es el que se habla en España y que el verdadero inglés es el de Inglaterra, no el que se enseña acá. ¿Te has puesto a pensar cómo sería tu interacción con el profesor si lo trataras de vos? Y si un desconocido en la calle te pide la hora diciéndote “¿Qué hora tenés?”, ¿cómo te sentís? ¿Acaso sos de aquellos que prefieren que les traten de usted, por eso de “¿que acaso te conozco?” o “¿acaso hemos comido en el mismo plato?” Es posible que tú pensás que si te llaman de usted podrían decir que sos "muy estirado, cuadrado o viejo". Quizás no querés que te llamen de tú porque eso suena muy "fresa", como se dice popularmente. A estas alturas quizás usted se está preguntando si hemos comido en el mismo plato para que le estemos voseando. ¡Vos no sabés con quién estás hablando!

De las muchas variables lingüísticas que existen en una comunidad, las formas pronominales son probablemente las que mejor reflejan la relación social entre hablantes y de éstos para con su grupo social a partir de variables lingüísticas. En la variación salvadoreña del español (y buena parte del continente americano) existen tres formas pronominales para la segunda persona del singular: usted, tú y vos. 
Usar tú, usted o vos nos complica la vida porque el trato pronominal es una actividad desafiante en nuestro español. Si bien usamos la forma pronominal de forma inconsciente la mayoría de veces, también es cierto que en muchas otras ocasiones hacemos una decisión premeditada al "tratar" a otra persona. Este artículo tiene como propósito analizar el origen y el valor semántico del pronombre vos en relación a los pronombres tú y usted en la variación salvadoreña del español.

\section{El origen del vos}

El vos viene del latín y representaba respeto hacia una figura de autoridad, muy distinto al vos que usamos en nuestros días. En latín, tu era exclusivo de la segunda persona del singular mientras que el vos era la forma pronominal de la segunda persona del plural. Paez Urdaneta ${ }^{4}$ analiza el desarrollo histórico del vos y se decanta por la hipótesis de Brown y Gilman ${ }^{5}$ en la que el uso del vos para referirse a una persona comenzó a usarse en los comienzos del siglo IV o finales del V, d.C. para dirigirse a un emperador romano. De manera que las palabras dirigidas a un emperador implicaban la existencia de otros emperadores en un momento en la historia en el que hubo más de un emperador de Roma ejerciendo poder a la vez. La adición del vos creó un paradigma con un vos reverencial y un tu para otras interacciones con un interlocutor. Con el tiempo el vos comenzó a ser usado también por aquellas personas que no pertenecían a la aristocracia. Páez Urdaneta apunta que la adopción del vos para dirigirse a otras personas que ejercían algún tipo de autoridad política o religiosa no tardó en socializarse o difundirse, aunque en forma progresiva. Esto habría producido que coexistieran el pronombre tu para alguien sin autoridad, vos para alguien con autoridad y el vos plural para más de un interlocutor, con o sin autoridad.

Hacia los siglos VI y VII el paradigma de uso pronominal se habría complejizado. El vos habría agregado un valor adicional. Además de ser un pronombre reverencial, pasa a ser también un pronombre de cortesía y respeto, alternando con el tu aun cuando las personas no representaban una autoridad y en situaciones en las que se esperaba un favor o beneficio por parte del otro. Estas variaciones en el tratamiento pronominal fueron asimiladas por el "latín vulgar" o "latín coloquial" en forma gradual y con diferentes usos según la región. Si bien todas las lenguas romances mantuvieron la diferencia de número gramatical, singular y plural, entre tu y vos así como el uso reverencial antiguo

4 Páez Urdaneta, Iraset, Historia y geografía hispanoamericana del voseo, 15-59.

5 Brown R. \& A. Gilman, The pronouns of power and solidarity. Language and Social Context: selected readings. 
del vos hacia una autoridad como el Rey o el emperador, no todas las lenguas desarrollaron el uso del vos para expresar cortesía y respeto hacia personas que no necesariamente ostentaban un poder o una autoridad política. Este uso del vos se masificó entre las clases populares en idiomas como el francés y el español, por ejemplo.

Para el caso del español, ya en el siglo XV y XVI el uso del vos de la segunda persona del singular entre individuos de clases inferiores se habría generalizado a tal grado que se convertiría en una ofensa para las personas de clases sociales altas, para quienes el trato con el vos era, en un principio, un reconocimiento de autoridad y estatus social. Paez Urdaneta ${ }^{6}$ muestra escritos en los que se refleja el sentir hacia el uso del vos en aquella época:

“...le dixe sin pensar enojallo: 'Belmar, vos jugáis mal'; alterándose él por el vos que les dixe, respondió, empuñado y feroz: 'Yo juego bien, y vos, que sois tú, sois muy ruin hombre" (año 1566)

"El secretario Antonio de Eraso llamó de vos a Guiterre López, estando en el Consejo (Real) y por eso se acuchillaron” (año 1579)

"Quien llamase de vos a otro, no siendo muy más calificado, le menosprecia y hace ultrage en nombralle, pues se sabe que con semejantes palabras llaman a los peones y trabajadores" (año 1953)

"Sepa que los españoles reciben un bofetón cada vez que los tratan de vos..." (año 1615)

“...tú, que se da a los niños o a las personas que queremos mostrar grande familiaridad o amor. Vos se dice a los criados y vasallos." (año 1619)

"De vos tratamos a los criados y mozos grandes...y entre amigos adonde no hay gravedad ni cumplimiento se tratan de vos" (año 1626)

La connotación negativa del vos permitió la introducción de una nueva forma de trato pronominal en y hacia las clases superiores: vuestra merced. Dicha forma adoptó los valores de respeto y cortesía en el trato con un interlocutor. Con el tiempo, vuestra merced simplificaría su forma a usted en los siglos posteriores. Ya en el siglo XVIII se tendría un sistema pronominal compuesto por tres pronombres tú, vos, usted del que actualmente permanecen tú y usted en el español ibérico. 
En el español peninsular, el tú y el usted han sustituido los valores semánticos que el vos tuvo en algún momento. Por un lado, el vos otorgado a los trabajadores y clases inferiores ha sido sustituido por tú, y, por otro, vos de respeto, de reverencia y de cortesía ha sido reemplazado por usted. Hay que señalar que el tú siempre se ha mantenido constante como término que encierra la cercanía, igualdad, amistad e intimidad, a pesar de los diferentes cambios en el trato pronominal. Además, el vos como persona del plural continúa en la forma de vos + otros.

En América heredamos un sistema pronominal que atravesaba cambios importantes en la península ibérica. Se mencionó anteriormente que el sistema pronominal en la España hacia el siglo XVI se caracterizaba por un extenso uso del vos por las clases populares y lo negativo que ello resultaba en las clases altas. Pues bien, los conquistadores españoles trajeron consigo un español popular pero también culto, el cual se impuso, enseñó y asimiló a lo largo de los años. No sólo vinieron personas de clase baja, sin educación y malhechores; también acompañaron personas cultas y educadas en las ciencias, en la religión y la cultura correspondiente a la sociedad europea de la época. No obstante, la conquista lógicamente supuso nuevos dueños de la tierra, nuevos "señores", que reclamaban un trato acorde a la nueva clase dominante. Es probable que esto provocara un intenso uso del voseo, un trato lingüístico de respeto y cortesía hasta el punto de generalizar su uso como trato pronominal en buena parte la colonia española. Hay que mencionar, sin embargo, que se puede diferenciar regiones en el que predomina el voseo o el tuteo.

Ese trato constante con España y la influencia de ésta permitió que los cambios lingüísticos que se sucedían en la Península, del vos al tú y usted, también se trasladaran a estas regiones de tuteo en América. Podemos suponer que el voseo fue menor en aquellas regiones que tuvieron un mayor grado de contacto y de trato comercial y cultural con la península ibérica como lo fue el caso de grandes partes de México y de Perú. No fue así en otras regiones de voseo como en el sur de México y en Centro América, en las que su grado de relación con España fue menor debido a que, siendo una región mayormente agrícola, no contaron con muchos recursos de explotación que tanto encantaban a los españoles. De esta manera, para la segunda parte del siglo XVI ya se perfilan zonas marcadas por usos pronominales dominantes de vos o de tú con matices propios.

Además de mantener zonas de voseo y tuteo, el español americano tiene otras particularidades. Por ejemplo, se caracteriza por no haber asimilado el desarrollo en España de la segunda forma del plural vos-otros/vos-otras, lo cual 
en América se expresa con el plural de usted, ustedes. También, las formas del verbo que corresponden al vos hispanoamericano reducen la conjugación verbal para vosotros en el español ibérico. Así por ejemplo, podemos comparar las siguientes dos oraciones poniendo atención a la semejanza de cada uno de los verbos conjugados:

con el vos:

tenés que leer este artículo ahora aunque lo podés hacer cuando tengás tiempo

con vosotros:

tenéis que leer este artículo ahora aunque lo podéis hacer cuando tengáis tiempo.

El uso del vos, entonces, se dio como una respuesta a la necesidad de mostrar respeto hacia cierta clase social, pero se transformó en un pronombre de uso popular. Vuestra merced se convirtió en usted, luego de sufrir cambios "vuestra merced > usarced > usted", y hasta hoy en día se mantienen las abreviaturas antiguas para usted: Vd. o Ud. En España no sobrevivió el uso popular del vos, pero se mantiene en lo religioso como lo demuestra De la Fuente7:

¡Oh Señor!, confieso vuestro gran poder. Si sois poderoso, como lo sois, ¿qué hay imposible al que todo lo puede? Quered Vos, Señor mío, quered, que aunque soy miserable, firmemente creo que podéis lo que queréis, y mientras mayores maravillas oigo vuestras y considero que podéis hacer más, más se fortalece mi fe y con mayor determinación creo que lo haréis Vos. ¿Y qué hay que maravillar de lo que hace el Todopoderoso? Bien sabéis Vos, mi Dios, que entre todas mis miserias nunca dejé de conocer vuestro gran poder y misericordia. Válgame, Señor, esto en que no os he ofendido. Recuperad, Dios mío, el tiempo perdido con darme gracia en el presente y porvenir, para que parezca delante de Vos con vestiduras de bodas, pues si queréis podéis.

\section{Teoría de los pronombres}

En el campo de la sociolingüística se analiza la relación que existe entre un idioma y sus hablantes. Es decir, como un idioma está constituido por sonidos, 
léxico, el significado y el orden de sus palabras y frases en una oración. Eso constituye la competencia lingüística de los hablantes. Pero igual de importante es la competencia sociolingüística de los hablantes. O sea, analizar el cómo un idioma es usado para expresar diversos propósitos (expresar cortesía o desprecio, distancia o cercanía, desprecio o cercanía, etc.) a partir de consideraciones que no son propiamente lingüísticas tales como el sexo, la edad, el estatus social, el contexto, etc. de la personas con quienes interactuamos.

Ha habido varios estudios para explicar el fenómeno de los pronombres en diferentes idiomas. El análisis clásico es el de Brown y Gilman ${ }^{8}$, The Pronouns of Power and Solidarity, quienes en aquel momento propusieron un modelo de trato pronominal basado en la estratificación social: en el poder semántico y el estatus social. Aplicado a nuestro idioma, la forma pronominal usted lo representaremos con $\mathbf{V}$ mientras que vos-tú se representará con la letra $\mathbf{T}$ (Vos y Tu del latín). La relación se describe en términos de reciprocidad. Así, la relación simétrica es reciproca y la relación asimétrica es una relación no recíproca.

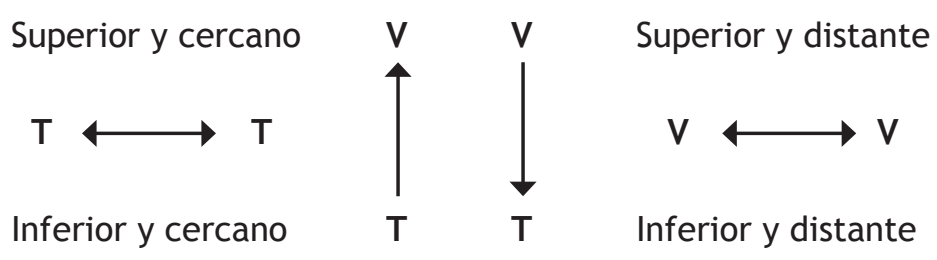

Las relaciones asimétricas, son aquellas en las que una persona envía $\mathrm{V}$ pero recibe $\mathrm{T}$, o viceversa. Este es un tipo de relación vertical y de poder relativo en el que quien ostenta un puesto inferior envía $\mathrm{V}$, pero recibe $\mathrm{T}$ por quien tiene un puesto superior. Se puede decir que esta relación puede describir distancia o respeto. Por ejemplo, el jornalero le dice usted al patrón, pero el patrón en cambio le llama con el vos. Es muy común que a los papás uno se dirija con usted, pero ellos lo hacen con el vos. Invertir este tipo de relación podría traer consecuencias o castigos, dependiendo del grado de "irrespeto" que se perciba.

Las relaciones simétricas, o relaciones horizontales, tanto el que se dirige como el que responde concuerdan con el pronombre usado, sea éste V-V o T-T. Las relaciones simétricas describen aquellas situaciones de cercanía, amistad, afecto, igualdad. Por ejemplo, lo usual es escuchar a hermanos, compañeros de clases en la universidad, esposos (después de cierto tiempo) tratarse con el

8 Brown R. \& A. Gilman, The pronouns of power and solidarity. Language and Social Context: selected readings. 
vos. Lo contrario no es la norma y suscita preguntas como ¿porqué se tratan de usted? ¿Acaso no se conocen? Algunos prefieren que no les digan usted porque “me hacés sentir mayor".

Las relaciones simétricas también pueden implicar distancia o respeto. Braun` explica la reciprocidad como una relación en la que existe una reevaluación de la condición social del otro que conduce a una simetría T-T en caso de cercanía mutua como en el caso de los compañeros de clase quienes suelen tratarse de vos. También la relación podrá ser $\mathrm{V}-\mathrm{V}$ en caso de distancia o respeto mutuo como cuando dos colegas de trabajo que se tratan de usted, aunque en igualdad de condición laboral y con un mismo salario. Suele suceder que un joven queriendo conquistar a una damisela comienza hablándole con usted, para no parecer "un abusivo"; sin embargo, luego de algunos días, o una vez consumado el noviazgo, cambian a una relación simétrica T-T. Hay que hacer notar que una vez que en esa relación se cambia de V-V a T-T no hay cambio a la inversa. Es decir, los novios que ahora se tratan usando el vos no vuelven a llamarse con usted en el trato cotidiano.

Desafortunadamente, el modelo antes descrito no es suficiente para describir completamente el uso de nuestro trato pronominal actual ya que las relaciones verticales y horizontales representan situaciones en una constante sin alteraciones de la siguiente manera:

T-V o V-T: relación asimétrica de poder desigual, respeto y sumisión a la persona que ocupa una posición superior.

T-T: relación simétrica de cercanía, igualdad y amistad entre dos en un mismo nivel (superior o inferior)

V-V: relación simétrica de respeto, deferencia, distancia entre dos en un mismo nivel (superior o inferior)

No obstante, habrá que tomar en cuenta también las variaciones lingüísticas de la forma pronominal producidas por la inversión o el rompimiento de las relaciones esperadas en la interacción. El modelo anterior indica que la relación T-V o V-T es aquella en la que quien está en posición inferior envía usted y quien está en posición superior envía vos, como cuando el cliente a quien le lavaron el carro no está satisfecho con el trabajo, se acerca al empleado y le dice con

9 Braun, Friederik, Terms of address: problems of patterns and usage in various languages and cultures, 15. 
desprecio "Mirá, vos, cipote!”, el joven con cierto temor le contesta "dígame, señor”, a lo que prosigue el cliente "decile al dueño que venga!”. Lo anterior es lo esperado. Lo que llama la atención es que el amo ordene a su mascota “váyase para afuera!". En ocasiones familiares, el padre se sienta con su hijo en tono serio para decirle "hijo, quiero hablar con usted". La mamá dice a su hijo con mucho afecto “¿qué quiere comer hoy mi niño lindo?”, o como un regaño “deje de molestar!”. Por el contrario, se escucha con más frecuencia que los hijos hoy en día tratan de vos a sus padres, lo cual hace un par de décadas no era usual. En estos casos hay una inversión en la relación esperada, de manera que quien está en posición superior envía $\mathrm{V}$, usted, y quien está en posición inferior, envía T, vos.

Si bien es cierto que T-T y V-V reflejan relaciones simétricas, del rompimiento en esta asimetría también se obtiene información diferente. Aquella pareja de novios que ahora en condiciones normales se tratan con el vos, la novia molesta responde al cortejo del novio: “¡¿Qué quiere?! ¡Mejor no me diga nada que no me tiene contenta!". Estando en igualdad de condición (a menos que sea una novia golpeadora), el uso del pronombre usted (implícito por la conjugación del verbo) pretende establecer distancia con su pareja. También se ha observado que dos personas peleando, aún siendo adultas y con uso de razón, crucen expresiones de reto: “¿y vos quién creés que sos? ¿Creés que te tengo miedo?” El uso del vos en este caso refleja desdén y menosprecio visto como si desde una posición superior se tratara, más que a nivel de igualdad o cercanía.

La variabilidad de las formas pronominales para la segunda persona del singular parte de la existencia de variedades marcadas y no marcadas en la competencia sociolingüística de los hablantes. Saville-Troike ${ }^{10}$ define una variedad como patrones sistemáticos en las formas y usos del lenguaje, reconocidos por los hablantes de una comunidad lingüística como entidades que difieren entre sí en forma significativa. Así, las variedades no marcadas son variedades esperadas, normales y simples, como las propuestas por Brown y Gilman. Por el contrario, las variedades marcadas son complejas e inesperadas, como sucede con el rompimiento de las relaciones simétricas o la inversión en V-T o T-V. La complejidad en este caso es de tipo perceptual o sicológica. Al explicar cómo es que una persona comprende una variedad, Saville-Troike argumenta que los hablantes tienen un concepto de naturalidad que aplica tanto para su lenguaje en general como para cualquier contexto lingüístico, por lo que las variedades marcadas a niveles más generales llaman la atención hacia sí mismas.

10 M. Saville-Troike, The ethnography of communication: an introduction, 48-60. 
Según Watts ${ }^{11}$ las variedades no marcadas se pueden explicar a partir de comportamientos políticos. Un comportamiento político es uno cuyo objetivo es mantener un estado de equilibrio en las relaciones personales entre los miembros de un grupo social durante la interacción, tomando en cuenta aspectos extralingüísticos tales como el propósito comunicativo, el contexto, expectativas, sexo, edad, estatus quo, etc. En la misma línea, Scollon ${ }^{12}$ sostiene que los hablantes asumen aspectos extra lingüísticos así como del trato que piden para sí mismos y del trato que quieren conceder al otro participante en un acto comunicativo. Así, la selección de una forma pronominal no marcada inicia con el análisis y presunción de esos aspectos extra lingüísticos. Según la retroalimentación recibida, se podrá mantener o romper el balance en la interacción. Saltan las preguntas ¿son vos y tú usados por igual? ¿Es lo mismo llamar a alguien con vos que con tú? ¿Qué valor le da la sociedad al uso del vos con relación al tú?

\section{Los dominios del tú}

En El Salvador, el sistema educativo tradicional nos ha enseñado que en el español estándar la segunda persona del singular es tú. Con mucha fidelidad reproducimos el paradigma de pronombres cuando se nos pregunta ¿cuáles son los pronombres en español? A lo que contestamos: “yo, tú, él, nosotros, vosotros, ellos” y a la hora del receso se oye decir “ipasame la pelota, vos!”. No pocos son los eruditos y maestros de la gramática del castellano que promueven un mejor estatus del pronombre tú dentro de una lengua culta. Algunos incluso han tenido pensamientos adversos para con el uso del vos. Andrés Bello ${ }^{13}$ por ejemplo, llegó a decir que:

no debe usarse en la conversación el pronombre vos; porque si se habla con una sola persona, se debe decir usted o tú, según el grado de familiaridad que tengamos con ella, y si son muchas personas, ustedes o vosotros...Pero no sólo se peca contra el buen uso usando a vos en lugar de tú, sino (lo que es aún todavía más repugnante y vulgar) concertándole con la segunda persona de singular de los verbos. Vos se ha de considerar siempre como plural...Por consiguiente, es un barbarismo grosero decir, como dicen muchos, vos eres, en lugar de vos sois o tú eres.

\footnotetext{
11 Watts, Richard J. Linguistic politeness and political behaviour: reconsidering claims for universality. Trends in linguistic studies and monographs, 59.

12 Scollon, Ron \& Suzanne Wong Scollon, Intercultural communication: a discourse approach, 45.

13 Bello, Andrés, Obras completas de Andrés Bello: Estudios gramaticales.
} 
El ámbito de la religión no escapa a los dominios del tú. Es de recordar que la biblia traducida al español está escrita con la conjugación verbal que corresponde al pronombre tú cuando se refiere a la segunda persona del singular. Al escuchar pastores o religiosos que elevan sus plegarias al cielo, le hablan a Dios utilizando el pronombre tú. La mayoría, si no todos, los cánticos y alabanzas no parecen incluir una forma verbal conjugada con el vos. ¿Acaso a Dios le enoja que le hablen con el vos? A lo mejor a Dios no le incomode, pero a sus adoradores les podría parecer que están irrespetándole. Tal es el caso que en algunas iglesias evangélicas le oran usando usted, "le pido que nos proteja y nos libere del mal..."

Los medios de comunicación exaltan el uso del tú. Al escuchar las noticias en la televisión, los anuncios durante los intermedios, novelas y las absorbentes campañas electorales, se escucha usar ya sea el pronombre tú o diferentes formas verbales que corresponden al pronombre tú, "sólo tú puedes cambiar el futuro...", "comienza bien el día con...". Las entrevistas a funcionarios políticos en la televisión se dirige usando usted o tú, pero rara vez o nunca con el vos. La prensa escrita y programas radiales también se empeñan en el uso del tú cuando se dirigen al lector o al radioescucha. Pareciera que en nuestro dialecto del español la segunda persona del singular se debe de expresar con el tú, el pronombre de "lo correcto" ante el público o una audiencia.

\section{Una propuesta: nosotros voseamos, ¿nos acompañás?}

En El Salvador, el pronombre para la segunda persona del singular que realmente se utiliza en el diario vivir no es el tú. Al contrario, en la realidad y el día a día hay un uso intenso del vos como un pronombre familiar y de uso popular. Muchos de los mismos profesores de escuela que se esmeran por enseñar a sus alumnos como conjugar los verbos con el tú se dirigen a sus estudiantes con el vos. Se enseña lo que no usamos, usamos lo que no aprendemos en la escuela. El uso del vos permea la lengua de muchos, si no la mayoría, de los pastores, feligreses, periodistas, políticos, publicistas, etc.

Aquí se vosea con intensidad y por norma. Se intenta dar la imagen que se tutea, pero la conjugación verbal que usamos es de tal fuerza reveladora que nos delata inmediatamente. Las construcciones híbridas dicen de la naturaleza del pronombre que usamos y que hemos adquirido como lengua materna. En varias ocasiones se escucha a los locutores juveniles más populares preguntar a su audiencia "¿y tú como te llamás? ¿Hola tú, que me contás, que hacés?, ¿Y tú que pensás al respecto?" Parecería que estas construcciones híbridas pretenden seguir el patrón que se ha enseñado desde la escuela, dando un estatus diferente 
a tú ya sea porque "suena mejor" o porque "es más educado", aunque la conjugación verbal se empeñe en demostrar que en realidad voseamos.

¿Seremos capaces de legitimar y normalizar el uso del vos y su enseñanza en la educación formal? Aunque sea menester del Ministerio de Educación y entidades de cultura promover y potenciar la enseñanza del vos en las escuelas como parte inherente de la identidad cultural de los salvadoreños de manera que su uso sea normal en todos los ámbitos de la vida social, somos nosotros, los usuarios de la lengua, quienes debemos aceptar nuestra prerrogativa lingüística.

El voseo es parte de lo que nos identifica como salvadoreños tan pronto hablamos. Podremos vestir ropa de lujo, comer pupusas y pizza con un tenedor, cambiar el color del cabello y comportarnos como que pertenecemos a otra cultura. Sin embargo, hay algo que no podremos ocultar y que nos delatará enseguida: nuestra forma de hablar. Culturalmente debemos aceptarnos como somos, sentirnos orgullosos de vosear como símbolo de $\mathrm{p}$ ertenencia a un país, una cultura y una región. El ejemplo por excelencia es el hablante argentino, quien no olvida ni su acento dialectal, ni el uso del vos aunque se establezca en otra cultura. Es un asunto de orgullo y pertenencia cultural.

En todo caso, es positivo valorar y validar el uso intenso que del vos hacemos los hablantes salvadoreños. Aboguemos por que se incluya en nuestro paradigma pronominal (yo, vos, usted, él, ella, nosotros/as, ustedes, ellos, ellas) y así enseñarlo a las nuevas generaciones sin tapujos ni recelos. ¿Nos acompañás?

\section{Referencias}

Bello, Andrés, Gramática de la lengua castellana. Volume 1. Madrid 1903.

Bello, Andrés, Obras completas de Andrés Bello: Estudios gramaticales. Fundación la Casa de Bello. Caracas 1981.

Braun, Friederik, Terms of address: problems of patterns and usage in various languages and cultures. Mouton 1988.

Brown R. \& A. Gilman, The pronouns of power and solidarity. Language and Social Context: selected readings. 252-82, 1960.

De la Fuente, Don Vicente, Escritos de Santa Teresa. Biblioteca de autores españoles. Desde la formación del lenguaje hasta nuestros dias. Universidad de Madrid 1861.

Páez Urdaneta, Iraset, Historia y geografía hispanoamericana del voseo. La Casa de Bello. Caracas 1981.

Rey, Alberto, Social correlates of the usage of Spanish "You" subject pronouns in Colombia (part two). Hispanic Journal. Vol. 15 n 2 Fall. 291-305 1994. 
Salarrué, Cuentos de barro. Edición del centenario. CONCULTURA, El Salvador 1998.

Saville-Troike, Muriel, The ethnography of communication: an introduction. Third Edition. Blackwell Publishing 2003.

Scollon, Ron \& Suzanne Wong Scollon, Intercultural communication: a discourse approach. Second edition. Blackwell Publishing 2001.

Watts, Richard J. Linguistic politeness and political behaviour: reconsidering claims for

universality. Trends in linguistic studies and monographs 59. 43-69 1992. 
